(6)

\section{OPEN ACCESS}

\section{Correspondence to}

Shane Neilson, Department of

English and Cultural Studies,

Chester New Hall 321,

McMaster University, 1280

Main Street West, Hamilton,

ON L8S 4L9, Canada;

neilss@mcmaster.ca

Accepted 17 July 2015

Published Online First

7 August 2015

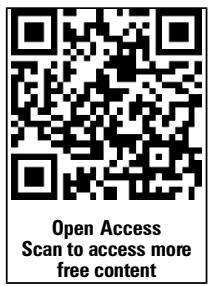

CrossMark

To cite: Neilson S. Med

Humanit 2016;42:3-10.

\title{
Pain as metaphor: metaphor and medicine
}

\author{
Shane Neilson
}

\section{ABSTRACT}

Like many other disciplines, medicine often resorts to metaphor in order to explain complicated concepts that are imperfectly understood. But what happens when medicine's metaphors close off thinking, restricting interpretations and opinions to those of the negative kind? This paper considers the deleterious effects of destructive metaphors that cluster around pain. First, the metaphoric basis of all knowledge is introduced. Next, a particular subset of medical metaphors in the domain of neurology (doors/keys/wires) are shown to encourage mechanistic thinking. Because schematics are often used in medical textbooks to simplify the complex, this paper traces the visual metaphors implied in such schematics. Mechanistic-metaphorical thinking results in the accumulation of vast amounts of data through experimentation, but this paper asks what the real value of the information is since patients can generally only expect modest benefits - or none at all - for relief from chronic pain conditions. Elucidation of mechanism through careful experimentation creates an illusion of vast medical knowledge that, to a significant degree, is metaphor-based. This paper argues that for pain outcomes to change, our metaphors must change first.

For most patients, pain is transient, lasting as long as the causal illness does. Then pain disappears. For other patients, pain transforms into a chronic problem that usurps identity. Both types of patients want release, for their ordeal to end. But in the language I just used, that of 'patients' and 'illness' and 'problem' and 'ordeal,' I have perpetuated a 'problem' that is consolidated in language. In her landmark study The Body in Pain, Elaine Scarry memorably pointed out that pain finds its way into language almost exclusively through metaphors of weaponry and damage. ${ }^{1}$ I build on this observation by arguing that pain is conceptualised and expressed through negative and destructive metaphorical systems that have been appropriated by physicians and entrenched with supplementary neurological metaphors. I argue further that the incredible accumulation of detail concerning pain pathways is dependent upon these destructive metaphor systems. The medical understanding of pain is reliant upon certain theoretical constructs that might be distant in time yet are influential in effect; elaborations upon these theories with experimental knowledge and minute elaboration of physical detail-the so-called 'mechanistic' view of paindo not change the metaphors we use to understand the physiological information. Because the benefit of seeing a medical practitioner skilled in the treatment of pain is modest, the accumulation constitutes a meaningless ubiquity, an authoritative edifice of medical knowledge that is an illusion of authority. That the authority derives from knowledge that is based on destructive metaphors should make anyone suffering from pain circumspect.

In Metaphors We Live By, a seminal text on metaphor, Lakoff and Johnson define metaphor as "a way of conceiving of one thing in terms of another, and its primary function is understanding". ${ }^{2}$ All disciplines resort to metaphor for the means of their understanding, and Lakoff and Johnson demonstrate how pervasive metaphorical thinking is, but also that much of our metaphorical thinking is based on arbitrary conventions that aren't preserved across cultures. Nietzsche contributed a strange property of metaphor in "On Truth and Falsity in their Extramoral Sense":

\section{What therefore is truth? A mobile army of meta- phors, metonymies, anthropomorphisms: in short a sum of human relations which became poetically and rhetorically intensified, metamorphosed, adorned, and after long usage seem to a nation fixed, canonic and binding; truths are illusions of which one has forgotten that they are illusions". ${ }^{3}$}

Disciplines progress according to the strength of their metaphors, and those metaphors are fated to become so familiar that they transform into illusions, if even thought of at all. Nietzsche adds that in an earlier age, it was

\begin{abstract}
language which has worked originally at the construction of ideas; in later times it is science. Just as the bee works at the same time at the cells and fills them with honey, thus science works irresistibly at that great columbarium of ideas, the cemetery of perceptions, builds ever newer and higher storeys; supports, purifies, renews the old cells, and endeavors above all to fill that gigantic framework and to arrange within it the whole of the empiric world. ${ }^{4}$
\end{abstract}

The scientific edifice will stretch past the sky like an endless erector set but it is still built on a core of metaphor. But what if the metaphors are inherently limiting, or even counterproductive?

The problem the man of science faces is that 'the impulse towards the formation of metaphors, that fundamental impulse of man' withstands and is even used to interpret the 'regular and rigid new world' that comes from the pursuit of knowledge and truth according to the scientific method. Scientific ideas, Nietzsche explains, are constantly confused by the construction of 'new figures of speech, metaphors, metonymies' such that the 'existing world of waking man' is ultimately rendered 'motley, irregular, inconsequentially incoherent, attractive, and eternally new as the world of dreams is'. ${ }^{4}$ Part of the problem inherent to this marriage of metaphor and scientific knowledge is that individual metaphors exist within 'a whole system of metaphorical concepts-concepts that we constantly use in living and thinking. These expressions, like all other words and phrasal lexical items 
in the language, are fixed by convention'. ${ }^{2}$ The scientific disciplines use their own cosmologies of metaphor with which to produce and disseminate understanding, and medicine's central pain metaphors that marshal a mobile army of truth are of weapons and damage, as per Scarry, but also metaphors of neurology that include doors, keys, wires and circuitry. ${ }^{\mathrm{i}}$

Pain was first codified by the International Association for the Study of Pain (IASP) in 1979 as "an unpleasant sensory and emotional experience associated with actual or potential tissue damage, or described in terms of such damage" ${ }^{\text {iii. }}$. A single sentence long, this abstraction cannot convey what pain is, what it feels like. Textbooks that recount medical history often point out that the definition includes the parameter of emotion, taking pain back from the clinical, hyperphysiological viewpoint of the 19th, 20th and 21st centuries. The discipline's definition is a negative one restricted to metaphors of damage. That this definition is consistent with the concept of pain operating in general society-pain as a negative experience-does not mean it is an adequate definition, for as Lakoff and Johnson show, our metaphors can work to increase or decrease understanding. It may be that the popular discourse around pain-pain as negative experience as expressed by metaphors of weaponry and damage-is, in metaphorical terms, the 'wrong road.' If pain can only be negative, then pain will only be used for negative purposes and have negative effects. This is an inherent obstacle to recovery from painful conditions. What is lacking in the IASP definition is the dissent of possibility, a description of transcendent effects, of how this undeniably unpleasant experience has useful results for individuals and for society. Perhaps the problem is a chronological one, for acute pain is a message of actual tissue damage, whereas chronic pain is usually pain signal without damage. (Even so, the language used here-one of 'damage'-implies a lack of value in the affected body part, a state of affairs contested by the burgeoning field of disability studies.) But the possible positivity of pain, and its metaphorical roots in acute situations, is a subject that can be taken up in another forum. For now, it is important to recognise that the IASP definition is influential and provides the dominant metaphor for the whole branch of pain medicine $e^{\mathrm{iii}}$ and that when I refer to pain I mean chronic pain.

What is often ignored by medical professionals is the part of the IASP that defines pain as an 'experience.' In present-day North America, pain is a clinical experience that is relegated to medicine for alleviation. In The Culture of Pain, David Morris asserts that " $[\mathrm{t}]$ he vast cultural shift that gives the story of pain its hidden plot centres on the eradication of meaning by late nineteenth-century science. . .[w]e are the heirs of the transformation in medical thought whereby we think of pain as no

\footnotetext{
${ }^{\mathrm{i}}$ As Lakoff and Johnson point out, humans "typically conceptualize the nonphysical in terms of the physical-that is, we conceptualize the less clearly delineated in terms of the more clearly delineated" (p. 59). ${ }^{2}$ Even if it is never explicitly stated in contemporary texts as such, the visual representation of cell membranes at the molecular level has a clear wire/door appearance.

iiThe importance of Canadian contributions to the understanding of pain cannot be underestimated. For example, the IASP definition was written by Merksey, a former professor of Psychiatry at the University of Western Ontario.

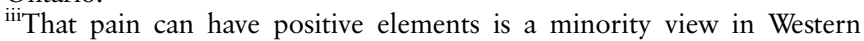
culture. Though medical histories approve of the inclusion of emotion in the IASP definition, they do not criticize the negative path researchers, huddled around the definition, have taken. Following the lead of medicine, culture has adopted medicine's view of pain as negative.
}

more than an electrical impulse speeding along the nerves". ${ }^{6}$ Medicine and the public use hegemonic metaphors to comprehend pain. Morris' text proceeds to examine how an inherently metaphorical understanding of pain absorbed by the larger public came into effect. There are problems with this wholesale relegation of pain to medicine and I will consider these problems at length in another forum. For now, the following summary of pain theories and their bases in metaphor constitutes a real narrative of progress. Textbooks like John Bonica's The Management of Pain, considered a standard in the field, briefly narrate the history of pain medicine in a single chapter before voluminously providing modern management principles. $^{7}$ In their abbreviated historical sections, such textbooks present pain as moving from primitive to a sophisticated understanding. In anatomical, physiological and biochemical terms, this is incontestable. Yet in a paradoxical way, the progress narrative has been, qua Nietzsche, obliterated by the metaphor of progress. Progress becomes the narrative, obscuring a truth which I hope to show is one of vast, systematic and elaborate oversimplification as encouraged by metaphorical understanding that conceals its nature as metaphor. Though neurological metaphors have assisted with the accumulation of scientific knowledge, their enshrinement as the means of understanding pain has had a terrible cost. We think of pain in terms of nerves, but nerves are not experience and nerves are not necessarily emotion. Nerves are not pain.

The first well-formed pain theory on record was derived by Aristotle (384-322 BC) who identified the affective component of pain. His work forms the foundation of much current understanding of the topic, and pain textbooks routinely invoke Aristotle's concept of pain as 'passion of the soul' because his definition corresponds with IASP's modern definition that includes 'emotional' experience. Yet pain textbooks provide the briefest mention of the four quoted words, leaving out Aristotle's complex definitions of 'passion' and 'soul.' Pain textbooks move on from Aristotle to similarly microquote from the humoral theory of Hippocrates, the next ancient theorist on a short (and curiously variable) list. From there, Galen. Onward to Descartes! There are a few other pain theories, but Aristotle's definition demonstrates the major problem inherent in the extreme summary by medical textbooks. Receding knowledge might be cited but is rarely understood, and it is the metaphors knowledge relies upon that are important, not knowledge itself.

Book I of De Anima begins by providing a historical survey on the topic of 'soul.' This is the text that sets out Aristotle's thinking about the nature of life. RD Hicks concluded from this book that Aristotle believes that "the attributes of soul cannot properly be separated from those of the body". ${ }^{8}$ In Book II, Aristotle furthers his investigation by launching into his own definition of 'soul.' In this foundational text cited by textbooks as proof of Aristotle's thinking on pain, pain is not a central concern-it is instead a minor topic enfolded under a much broader range of topics. Pain is really only theorised by Aristotle in the second part of Book III within a moral framework. With 30 chapters, De Anima requires more than four words of summary in order to understand what Aristotle truly means when he writes on pain. Pain cannot be understood out of context, including definitions of pain. Ironically, our underlying neurological metaphors short-circuit understanding.

Part of this context comes in Book II when Aristotle sets out the criteria for an organism to be called 'alive': (1) intellect, (2) sense, (3) locomotion and (4) motion of nutrition, growth and decay. He then moves to define what constitutes an animal: a living thing that distinguishes itself from other living things like 
plants on the basis of sense perception. This constitutes Aristotle's first serious mention of the senses. He mentions touch first out of the five senses in order to further substantiate what constitutes 'soul.' Touch is mentioned to assist with taxonomising life forms, not as a sense implicated in pain. In Chapter 3 of Book II, Aristotle puts pain squarely within an originating context of desire: "But all animals have at least one sense, touch; and, where sensation is found, there is pleasure and pain, and that which causes pleasure and pain; and where these are, there also is desire, desire being appetite for what is pleasurable". 9 Aristotle links pain and pleasure together in a moral framework. It should be clear at this point that the rerecapitulations of Aristotle by modern medical textbooks are quite decontextualised. How Aristotle is represented in pain textbooks goes a long way to proving the inadequacy of the pain textbooks as a group, for such texts constitutively reproduce 'passion of the soul' in what can be charitably referred to as catachresis and less charitably as mere historical adornment. If desire, pleasure and the good life entered into contemporary medicine's concept of pain, then our metaphors would not be the same. As corollary, our IASP-mandated 'experience' of pain would not be the same.

One other thinker deserves mention in brief due to his influential scientific and metaphorical contribution to pain. Rene Descartes (1596-1650) ${ }^{\mathrm{iv}}$, taking his cue from Aristotle, developed his theory of dualism in The Passions of the Soul (1649). The title and style of argument of this text are Aristotelian. Descartes likened the body to a machine and wrote that the mind is controlled by the soul, which he felt resided in the pineal gland (in opposition to the accepted view in his day that the soul resided in the heart). Descartes maintained that the nerves of the body were acted upon by the pineal gland through the medium of cerebrospinal fluid, a marked improvement over Hippocrates' humoral theory that suggested control over the body comes from the brain as mediated by neural structures. Descartes inaugurates the neurological metaphor for understanding pain, a development which reaches an apogee in the modern day. Ironically, Descartes' writings are densely metaphorical. Even his theory about pain perception is expressed in metaphorical terms: he maintains that pain travels from site of injury to the brain "just as, pulling on one end of a cord, one simultaneously rings a bell which hangs at the opposite cord". ${ }^{10}$ As per Morris, a culture's metaphorical system of nerves and pain is born. But like Aristotle, Descartes' thinking gets simplified over time and the complexity of pain is sidelined too.

Descartes is renowned as the great splitter of mind and body, the great dualist, but this perception is actually a disservice to his thought. Again, context is key, a fact literary scholar Jan Frans van Dijkhuizen demonstrates while writing about representations of pain in late mediaeval English literature. Consider the passionate fusion of mind and body in Descartes' six metaphysical meditations wherein it is proved that there is a God and that man's mind is really distinct from his body:

[T] here is nothing that this my Nature teaches me more expressly then that I have a Body, Which is not Well when I feel Pain [...] And by this sense of Pain, Hunger, Thirst, etc. My nature tells me that I am not in my Body, as a Mariner is in his Ship, but that I

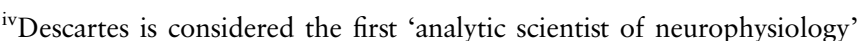
by Uhtaek Oh, the revisionist editor of hard-science textbook The Nociceptive Membrane. This is an example of how modern discourses penetrate the older ones and claim them for their own as a battle for primacy.
}

am most nighly conjoyn'd thereto, and as it were Blended therewith; so that $I$ with It make up one thing; For Otherwise, when the Body were hurt, I, who am only a Thinking Thing, should not therefore feel Pain, but should only perceive the Hurt with the Eye of my Understanding (as a Mariner perceives by his sight whatever is broken in his Ship). ${ }^{11}$

Clearly Descartes was not as absolute about the division between mind and body as is commonly perceived: pain complicates his otherwise strict dualism. Analysing the passage above, Jan Frans van Dijkhuizen asserts that pain "throws into doubt the very distinction between mind and body/matter which (Descartes) has first attempted to construct, since it points to the inescapable fact of human embodiment. Pain, more than any other physical sensation, confronts us with the fact that we do not just have bodies, but that we are our bodies". ${ }^{12}$ Writing that his body and mind are 'Nighly conjoined,' Descartes understood that pain complicates strict categories, making his pain concept much like that of Aristotle and the IASP, but constituting-as per the conventional narrative-an increment of progress. The scientific process selects certain findings and metaphors to create the narrative of progress, but the truth of our metaphors suggests a much more fertile field before the husbandry. Pain was and is more complex than our current metaphors allow.

Following Descartes, pain theorists included sensory and affective experience in their formulations but these remain abstract up to the present day. In the absence of real understanding or knowledge, the physiology of pain receives exquisite refinement instead. In the modern era, we talk about pain in the language of science, but the language of science remains, at bottom, the language of metaphor and 'as if' formulations masquerading as authoritative knowledge. I bring the reader quickly up to date by mentioning a few other pioneers in pain theory and research in order to sketch in the basis of medicine's neurological metaphors for understanding pain. In the 19th century, major advances were made in pain theory predicated on a greater understanding of neuroanatomy and neurophysiology. Though not alone, Charles Bell, a prominent Scottish neurophysiologist, laid much of the groundwork for what would eventually be known as specificity theory by writing in 1811 that

the external organs of the senses have the matter of the nerves adapted to receive certain impressions, while the corresponding organs of the brain are put in activity by the external excitement: That the idea or perception is according to the part of the brain to which the nerve is attached, and that each organ has a certain limited number of changes to be wrought upon it by the external impression.

That the nerves of sense, the nerves of motion, and the vital nerves, are distinct through their whole course, though they seem sometimes united in one bundle; and that they depend for their attributes on the organs of the brain to which they are severally attached. ${ }^{13}$

Bell's cold neuroanatomical descriptions, surgical induction of lesions and elucidation of resultant effects constitute a different kind of discourse in the Foucaldian sense- a medical, neuroanatomical and neurophysiological discourse. Bell's writings directly led to Johannes Muller's 'Doctrine of Specific Nerve Energies' from 1835, which is as follows: "The nerve of each sense seems to be capable of one determinate kind of sensation only, and not of those proper to the other organs of sense; hence one nerve of sense cannot take the place and perform the functions of the nerve of another sense". ${ }^{14}$ The presence of dissectible structures creates 'doctrines' that are 'specific'-the 
medical discourse is presented as authoritative even though its true knowledge at this point is vanishingly small.

Like all theories in any discipline, adherents to a given pain theory privilege their theory, resulting in intellectually gladiatorial pain discourses that compete in an academic arena for supremacy in terms of defining how to acquire knowledge. But because every pain theory works in an arena, the fallacy of supremacy is demonstrated. What is supreme is the medical discourse itself. By the term 'medical discourse,' I invoke Foucault's broad conception of discourse, including speech acts and social acts performed by medical and paramedical personnel that are directed and grouped around political and economic institutions like medical colleges, hospitals and journals. This discourse also includes the images used to represent pain and the symbolic meaning that culture attributes to those representations. Clinical in nature, medical discourse decontextualises experience in order to isolate pain as symptom and sign. In medical discourse, pain is expressed within language that is fundamentally negative in tone and implication-pain as disability, disorder and diagnosis. But what is truly powerful-the source of medical power and the illusion of power-is that pain is a problem misunderstood by neurological metaphors.

I begin this discussion of theory with the various theories that fall under the general category of pattern theory. Pattern theory was a prominent concept defined as "patterns of activation, spatial or temporal, in neurons that do not necessarily have timelocked responses to painful stimuli" ${ }^{15}$ This theory posits that there is more to pain than the labelled line extending from stimulus to brain. Rather, pain is signalled in a complex manner through parallel neural networks and processing. Though pattern theory has been around for over 100 years, it was elegantly articulated in 1965 with the gate control theory of pain by Ron Melzack and Patrick Wall, two researchers working at the Montreal Neurological Institute. This revolutionary articulation of theory-betraying reliance upon metaphor in the very name of the theory with the use of 'gate'-was presented as follows:

\footnotetext{
We propose that (1) the substantia gelatinosa functions as a gate control system that modulates the afferent patterns before they influence the $\mathrm{T}$ cells; (2) the afferent patterns in the dorsal column system act, in part at least, as a central control trigger which activates selective brain processes that influence the modulating properties of the gate control system; and (3) the T cells activate neural mechanisms which comprise the action system responsible for response and perception. Our theory proposes that pain phenomena are determined by interactions among these three systems. ${ }^{16}$
}

Laurence Kirmayer, the James McGill Professor and Director of the Division of Social and Transcultural Psychiatry at McGill University, interprets the theory like this: " $[\mathrm{t}]$ he key insight was the notion of central control of peripheral processes: that afferent control occurs at many different levels". ${ }^{17}$ Note the complexity of the gate-control construct as rooted in anatomy and concept. What is proposed is not one wire connected to another wire (ie, nerve A connects to centre B) but rather a multimodal, regulated system. The gate-control theory created an experimentally testable concept of pain that initiated a revolution in the understanding and treatment of pain. Kirmayer adds that the gate control theory "provided a natural conceptual framework to begin to integrate cognitive, psychological and ultimately social and cultural processes". ${ }^{17}$ As much of an advance as the gate control theory was, it is no more complex than a metaphor about policing a door. It is important to state this fact because complexity is often explained through the use of metaphor to provide understanding. What can be lost, what can seem illusory, is the basis of understanding. The complexity remains as science but the metaphor hides in plain sight as a commonplace. Our inconspicuous metaphors control our understanding but we are not aware of it. We amble through pain as unconscious beasts (figure 1).

And, in particular, we rely upon visual metaphors as our interpretive tools. Within the medical discourse, there is a system of visual metaphors for pain. Such images are meant to represent progress while ignoring their provenance as metaphor due to the special nature of image-that of concretised truth. Though images are intended to be a simplification of truth, contemporary schematic explanations of pain represent a hearkening back to 19 th-century specificity theory. Morris writes, "We are the heirs of the transformation in medical thought whereby we think of pain as no more than an electrical impulse speeding along the nerves". ${ }^{18}$ We are the heirs, and we are in an important way re-innovators of this idea. Although the present deluge of diagrams and textual explanations of pain don't argue for a return to specificity theory per se, they do pretend to an immense knowledge of how one wire connects to another wire, leaving out the affective dimension entirely. Mechanisms are emphasised in medical discourse. 'What is pain?' is a difficult question to answer, but opiate and GABA receptors can be identified, tested in experiments, and the results published in articles rich with schematics and diagrams. In this way, the simple is represented simply, demonstrating the secret and dangerous power of visual representations that avoid images of human beings in pain. Standing on the shoulders of schematics,
Figure 1 A schematic of gate control theory. Adapted from Melzack and Wall. $^{16}$

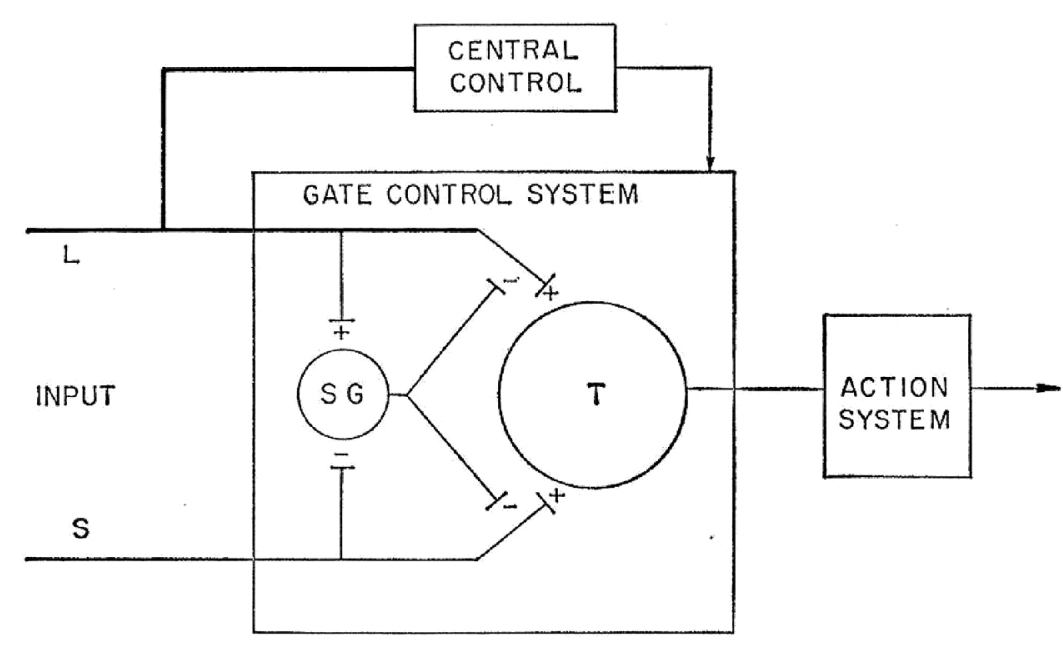

Neilson S. Med Humanit 2016;42:3-10. doi:10.1136/medhum-2015-010672 


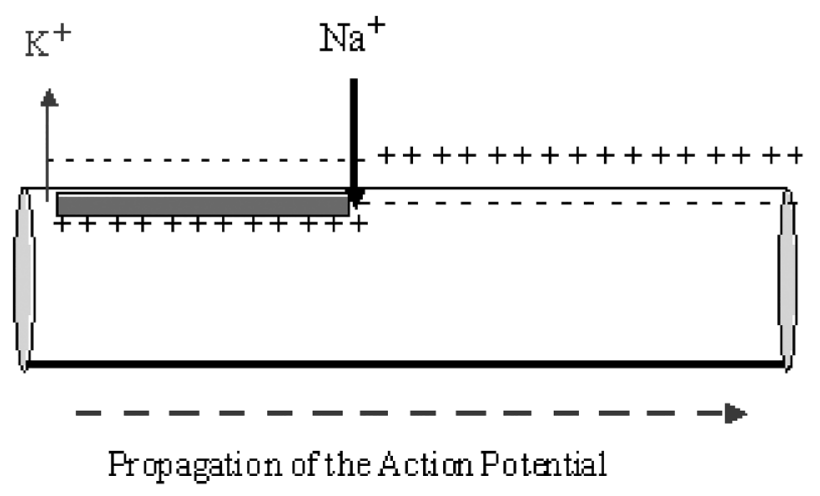

Figure 2 A schematic of action potential propagation. Adapted from Review of Membrane and Action Potentials (http://www.life.umd.edu/ classroom/bsci440/higgins/lecture2.html).

medicine appears powerful and knowledgeable. Yet the schematics are metaphors which perpetuate themselves to the detriment of complex truth. Schematics are visual metaphors that limit understanding because of extreme simplicity.

Pain medicine's learning curve is a way to police the door to understanding pain. To understand pain, one must first assimilate significant amounts of knowledge about basic neurophysiology. The state of neurophysiological knowledge, as opposed to pain perception, is advanced. Digesting basic explanations of how nerves conduct electricity like '[n]eurons communicate by producing electrical impulses called action potentials. Action potentials are self-regenerative electrical signals that tend to

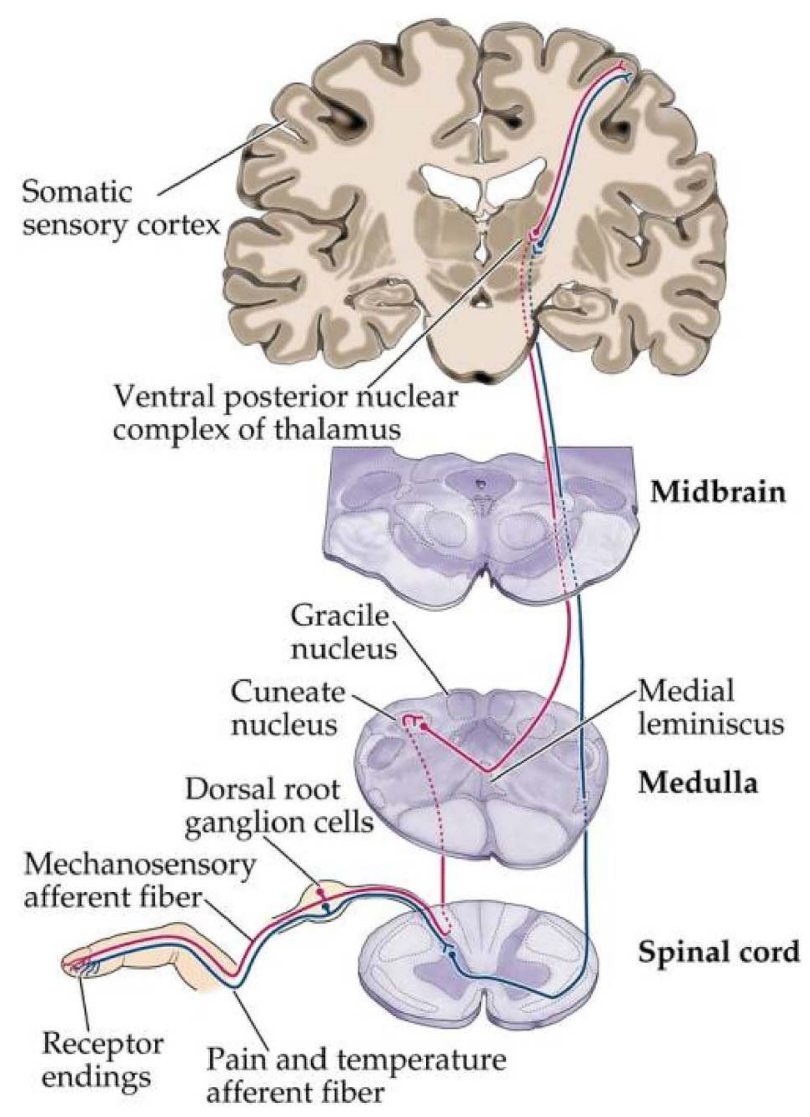

Figure 3 The spinothalamic pathway. Adapted from Somatic Sensory System (http://www.rci.rutgers.edu/ uzwiak/AnatPhys/ ChemicalSomaticSenses.htm).

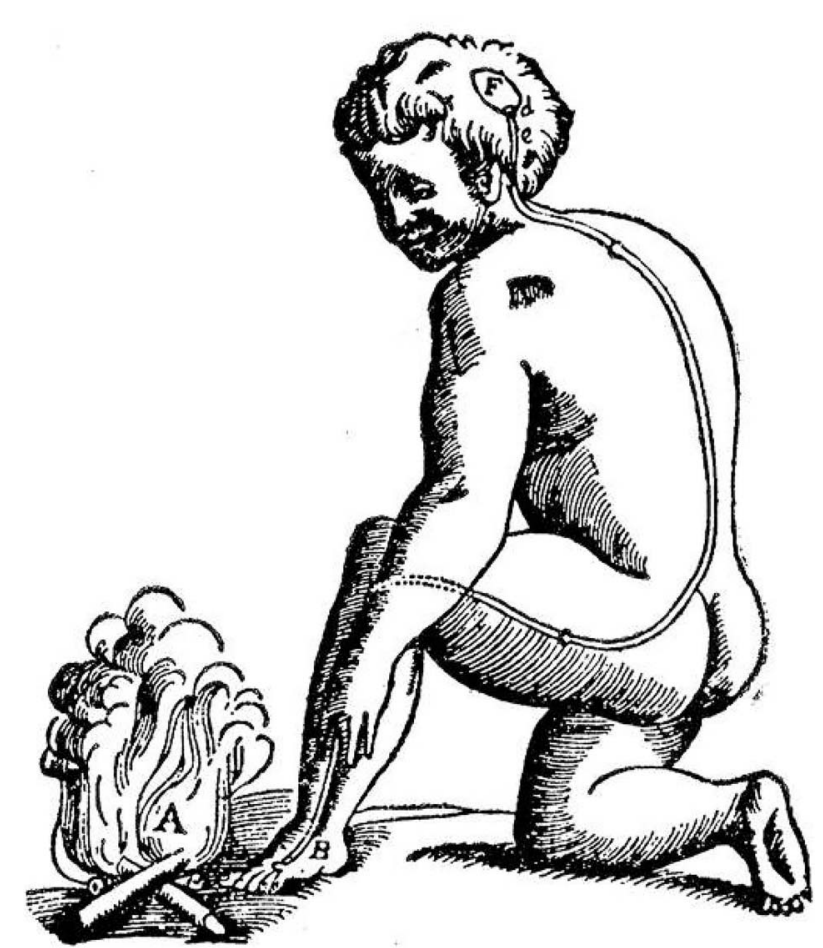

Figure 4 An illustration by Descartes to show fire 'pulling' a thread. Retrieved from Wikipedia (http://en.wikipedia.org/wiki/History_of_pain_ theory). Original illustration appeared in Descartes' Treatise of Man (1664).

propagate throughout a neuron and along its axon. The action potential is a depolarisation of about $100 \mathrm{mV}^{19}$ leads to the seductive inference that it's not just electric impulse that's conducted, it is pain that is conducted. This inference is true in that there are certain nerve fibres responsible for transmitting certain kinds of pain. But it's not true in that this signal is just that-a signal. It isn't pain. No nerve diagram with plus and minus signs on either side of a line representing a membrane turns knowledge into knowing (figure 2).

Who could look at such a diagram when in pain and say, 'This is pain!' Admittedly, no student looks to diagrams like the one above to understand what pain is specifically. Yet the unacknowledged metaphorical basis of the diagram (nerves are wires) and the fact that the diagram is a basic building block common in medicobiological texts, leads to the creation of a powerful metaphor-based illusion. Much of the understanding of pain gets relegated to a diagram such as this one. Although to understand pain, one must learn nerve signalling, one should also recognise that nerve signalling serves as the physiological basis of a metaphorical system. There is an illusion that more is known as the state of current knowledge is vast in terms of intricate mechanisms. Distortions occur among those without training and even those with training, because of the nature of scientific progress identified by Nietzsche. There is more to pain than can be metaphorically illustrated by 'nerves', but a neurophysiologist too can quickly forget what is only partially apprehended by the hegemonic metaphors. For example, incredibly detailed mechanistic explanations of pain add little to the IASP definition of pain. The following words from the domain of molecular biology prove the point:

The magnitude and nature of leak conductance determines membrane resistance and the impact a generator current will have on 


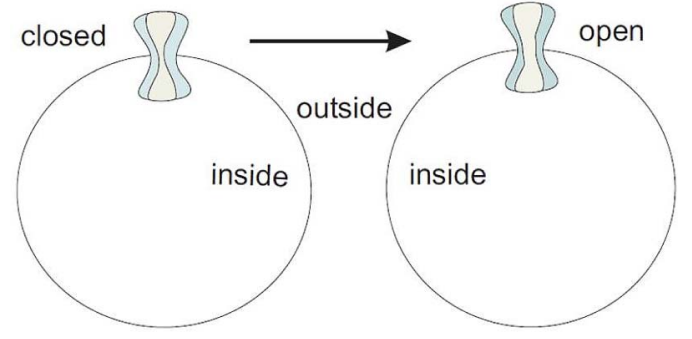

Figure 5 Diagram from p. 2-4 of Allan Fein's Nociceptors and the Perception of Pain, 2012.

\begin{abstract}
the membrane potential. . . [g]iven the fact that there is considerable variation in the biophysical properties of $\mathrm{Na}+$ channels depending on which (alpha) and (beta) subunits are present, the relative density of these subunits will have a significant impact on action potential threshold. ${ }^{20}$
\end{abstract}

Knowing which subunit communicates with another is important at the level of possible intervention sites for pharmacological therapy, but this knowledge does not augment the IASP definition. Yet such is the frontier of pain research, a perpetual spelunking of microdetail that fills the pages of the most prestigious journals. Pain researchers investigate the domain of receptor, ion and protein fold. Molecular biology, neurophysiology and reproductive neurobiology are the ascendant medical discourses of pain, and they are intoxicating precisely because of their reductive power. The danger-and, I argue, implicit message-is that one doesn't need to bother with politics, religion or power when viewing such diagrams.

But one does. In Descartes' day and for some time before that, Christianity provided the Western world with a hegemonic pain discourse other than the medical. By building an iconography around Jesus Christ, Christianity used Christ's last days after re-entering Jerusalem (tellingly titled the 'Passion' in English) in a framework of human suffering-that pain serves as a conduit to God, that suffering intensifies one's relationship with the maker. This relationship was presented as a pleasurable and even sexual one. Albeit problematic, the Christian attitude towards pain is more positivist than that of the clinic. And ignoring politics in the conceptualisation of pain is to ignore the maimed, war-torn world that pain makes.

Mechanistic discourses are possibly inferior than religious ones in terms of articulating pain because of their inherent lack of meaning. When modern-day Rene burns his finger, he knows that physical pain is the result of nociceptors sending a signal from the periphery to the brain, as well as top-down processes modulating that same signal, as well as (perhaps) a God overseeing the process. But Rene also knows much more that science doesn't know yet: Rene knows he can reach for certain medications that will give him analgesia (he knows he can thank the mechanistic discourse for that) but if he wishes to make sense of his pain, his knowledge of the spinothalamic tract won't help him. If the fire was due to poor enforcement of building codes, or Rene lost his job due to a global financial crisis, turned to state-taxed alcohol in order to numb his pain, and inadvertently left a cigarette burning in bed, resulting in extensive burns. . . knowing wire A leads to wire B won't help Rene cope on the burn unit. He has a problem meaning, not a problem of neurology. Meaning is inherently bound up in metaphor and Rene needs better metaphors to reflect the complexity of his plight.

To demonstrate the rootedness of this problem of metaphor, I provide a specific series of diagrams that are metaphors masquerading as hard knowledge. Contextualisation in the form of narratives can expose the reductive nature of visual metaphors. Visual metaphors are the sine qua non of the medical pain discourse of the late 20th century onwards because they are more 'concrete' than those channelled by words. Consider figure 3, a diagram documenting the pain pathway as it relates to thermal sensation, one like it included in every textbook of pain (and ubiquitous on the internet):

The pedigree of the above diagram extends far back in history. Because the diagram shows a peripheral stimulus sending a signal to central structures (a wire system), the diagram is conceptually as simple as Descartes' thread running from the skin to the brain:

In figure 4, pain caused by intense heat 'pulls the string' of a nerve causing the tethered brain, now recognising the sensation of pain, to send a signal to the foot to withdraw. This call-and-response model chimes with contemporary diagrams of cell membranes, including the amorphous balls in University of

\section{Regenerative region Generator region Regentive region}

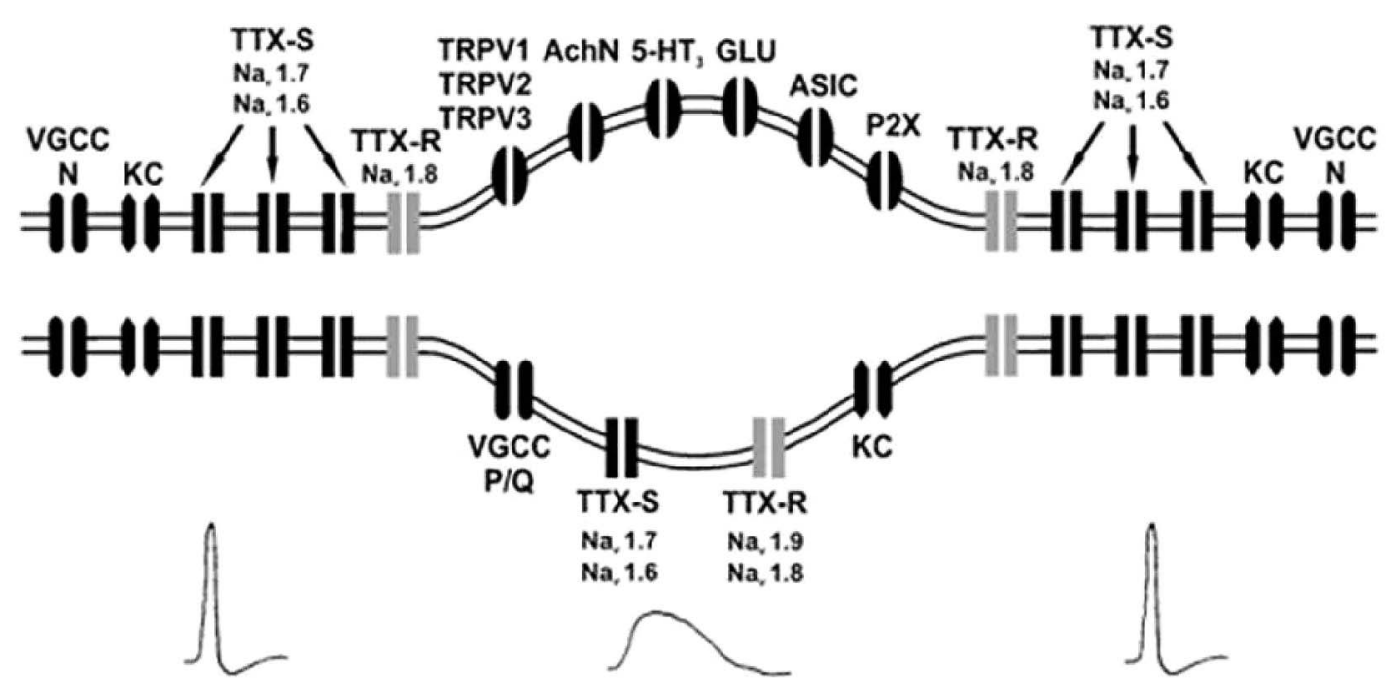

Figure 6 A schematic of ion channels. Adaptedfrom Uhtaek. ${ }^{21}$ 
Figure 7 Plate I from Charles Darwin. $^{22}$
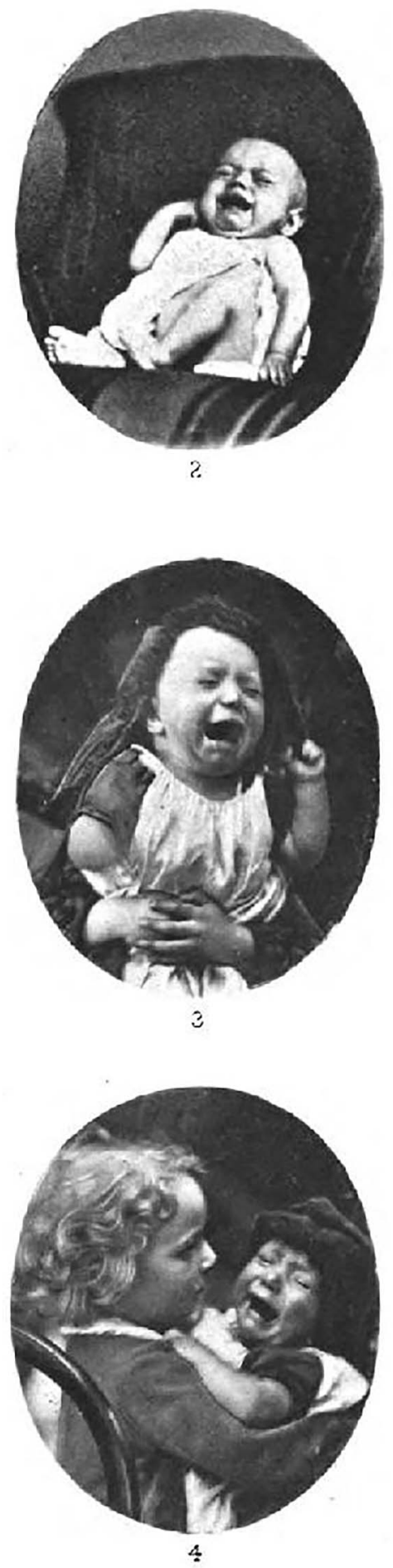
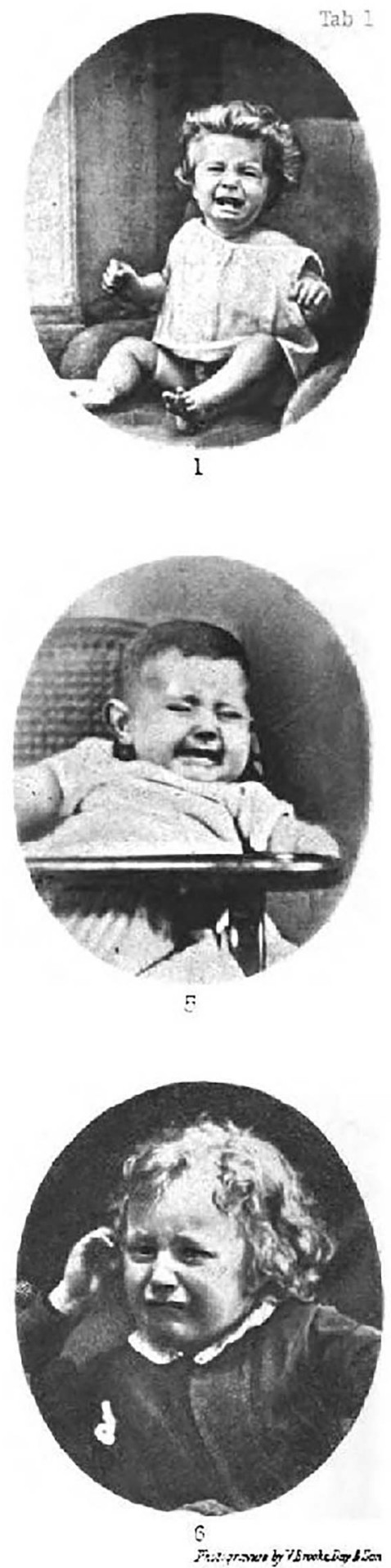

Connecticut professor Alan Fein's Nociceptors and the Perception of Pain (figure 5):

No more than a simple picture matching a simple concept, Fein's 'door' to the outside world opens in response to a stimulus. We remain in the metaphorical system of gate/door. What if the representation is more complex, such as one informed with contemporary neurophysiology?

The same ideology is at work in this diagram. At the level of superficial inspection, this diagram is more complex than Fein's, but on closer inspection it is just another wire/door metaphor with more elaborate knobs and tubes. Indeed, acronyms become the door's textual keys. Perhaps the image of the synapse comes closer to communicating pain experience than the spinothalamic tract diagram, for the synapse metaphorically represents the real gap between knowledge and knowing. But if metaphor is what's required to bridge the gap between knowledge and knowing, then science must be honest about its fundamental basis in metaphor.

The obvious riposte is that images like the one above are not meant to represent pain in total at all, that instead these figures demonstrate an infinitesimal piece of the puzzle of pain. But medicine focuses on these details to the detriment of the puzzle. 
The puzzle can never be solved because of the pursuit of parts. Elucidating components is simpler than understanding the whole. What's missing in these diagrams is the complex truth. The caption features a pile-up of acronymic explanations. To the non-specialist, images like these would seem like a perpetual wash, one spilling into the next that's meant to diagrammatise obscure molecular concepts. Figure 6 replicates the Cartesian human machine receiving some signal or other through means of doorbells and wires, albeit in a refined way. Yet the diagrams are no more informative than Descartes.

Consider the photographs included in Charles Darwin's The Expression of the Emotions in Man and Animals (1872) where photographs of infants in pain are included. Looking at these faces, are we not staring at (or in) the face of pain (figure 7)?

Contemporary science has offered an explanation of what is happening within the pictures and by the viewer of those pictures. Validated pain face scales quantify the level of pain experienced by the sufferer, and the work of Damasio, Tranel and Damasio has found that peripheral nociceptors connect to the thalamus, a structure that regulates emotional content. In turn, the thalamus sends a signal to the fusiform gyrus to effect consequent facial expression. ${ }^{23}$ Somehow the image of an infant in pain-knowing the infant is in pain-supersedes such scientific knowledge. An observer is moved by what she sees through an affective response. This interior drama matches the exterior one and is an important part of the narrative.

Medicine uses negative (damage/weapon) and neurological metaphors to the detriment of people in pain. How the uncertain and hypothetical nature of metaphor is elided in favour of the illusion of authority and competence has done pain sufferers a disservice. By accumulating mountains of mechanistic detail, the affective component has been lost as has the unstable nature of the understanding provided by science. Although negative and neurological metaphors explain pain to some extent, they are not sufficient. Other metaphors are necessary, as is realising the contribution of narrative to the study of pain. Pain is more than neurological metaphor. Pain is what we say it is over time. Pain is also the context in which we feel pain, and that context need not be a clinicoapocalyptical one of damage, weaponry or live wires.

Competing interests None declared.

Provenance and peer review Not commissioned; externally peer reviewed.
Open Access This is an Open Access article distributed in accordance with the Creative Commons Attribution Non Commercial (CC BY-NC 4.0) license, which permits others to distribute, remix, adapt, build upon this work non-commercially, and license their derivative works on different terms, provided the original work is properly cited and the use is non-commercial. See: http://creativecommons.org/ licenses/by-nc/4.0/

\section{REFERENCES}

1 Scarry, E. The body in pain: the making and unmaking of the world. New York: Oxford University Press, 1985:15.

2 Lakoff G, Johnson M. Metaphors we live by. Chicago: University of Chicago Press, 2003:36.

3 Nietzsche F. On truth and falsity in their extramoral sense. In: Shibles W, ed. Essays on metaphor. Whitewater: The Language Press, 1972:5.

4 Nietzsche, F. On truth and falsity in their extramoral sense. In: Shibles W, ed. Essays on metaphor. Whitewater: The Language Press, 1972:10.

5 Merskey, H. Pain terms: a list with definitions and notes on usage. Pain 1979;6 (3): 247.

6 Morris, D. The culture of pain. Berkeley: University of California Press, 1991:8.

7 Bonica, J. The management of pain. 2nd edn. London: Lea and Febiger, 1990.

8 Aristotle. De Anima. Trans. RD Hicks. Cambridge: Cambridge University Press, 1907:xxxvii.

9 Aristotle. De Anima. Trans. RD Hicks. Cambridge: Cambridge University Press, 1907:59.

10 Descartes R. Treatise of man. Trans. Thomas Steele Hall. Cambridge: Harvard University Press, 1972:34.

11 Descartes R. Six medical meditations wherein it is proved that there is a God and that man's mind is really distinct from his body, trl. William Molyneux. London: B.G. for Benjamin Tooke 1680:97-8.

12 Frans van Dijkhuizen J. Pain and compassion in early modern english literature and culture. Cambridge: D.S. Brewer, 2012.

13 Bell C. Reprint of the 'Idea of a New Anatomy of the Brain,' with Letters \&c. J Anat Physiol 1868;3:(Pt 1):147-82. US National Library of Medicine, 5 May 2014.

14 O'Malley CD, Clarke E. The human brain and spinal cord: a historical study illustrated by writings from antiquity to the twentieth century. 2nd edn. San Francisco: Norman Publishing, 1996:206.

15 Cervero F. "Pain theories". Science of pain. Basbaum A I, Bushnell MC. eds. New York: Elsevier, 2009:5.

16 Melzack R, Wall PD. Pain mechanisms: a new theory. Science 1965;150:971-9.

17 Kirmayer LJ. On the cultural mediation of pain." Pain and its transformations. Cambridge: Harvard University Press, 2007:68.

18 Morris D. The culture of pain. Berkeley: University of California Press, 1991:4. Print.

19 Waxman SG. Clinical neuroanatomy. 27th edn. New York: McGraw-Hill, 2013:20-1.

20 Gold MS, Caterina MJ. Molecular biology of the nociceptor/transduction. In: Basbaum Al, Catherine Bushnell M. eds. Science of pain. New York: Elsevier, 2009:56.

21 Uhtaek 0, ed. The nociceptive membrane. New York: Elsevier, 2006.

22 Darwin C. The expression of the emotion in man and animals. London: John Murray, 1872. Darwin Online, 14 May 2014.

23 Damasio, AR, Tranel D, Damasio H. Face agnosia and the neural substrates of memory. Ann Rev Neurosci 2014;13:89-110. 